\title{
Salpingitis Isthmica Nodosa
}

National Cancer Institute

\section{Source}

National Cancer Institute. Salpingitis Isthmica Nodosa. NCI Thesaurus. Code C40119.

Formation of nodules in the isthmus of the fallopian tube due to fallopian tube diverticulosis. It may cause infertility or ectopic pregnancy. 